\title{
Examination of the Effects of Vardenafil on Esophageal Function Using Multichannel Intraluminal Impedance and Manometry
}

\author{
Tae Hee Lee, ${ }^{1}$ Joon Seong Lee, ${ }^{1 *}$ Su Jin Hong, ${ }^{2}$ Seong Ran Jeon, ${ }^{1}$ Wan Jung Kim, ${ }^{3}$ Hyun Gun Kim, ${ }^{1}$ Joo Young Cho and \\ Jin-Oh Kim \\ ${ }^{1}$ Institute for Digestive Research, Digestive Disease Center, Soonchunhyang University Seoul Hospital, Seoul, Korea; ${ }^{2}$ Department of Internal \\ Medicine, Soonchunhyang University College of Medicine, Bucheon, Gyeonggi-do, Korea; and ${ }^{3}$ Department of Internal Medicine, \\ Soonchunhyang University Hospital, Gumi, Gyeongsangbuk-do, Korea
}

\section{Background/Aims}

To evaluate the effects of the phosphodiesterase type 5 (PDE5) inhibitor vardenafil on esophageal function, including bolus transit, using multichannel intraluminal impedance and esophageal manometry (MII-EM).

\section{Methods}

Sixteen healthy volunteers (15 men) underwent an MII-EM study including 10 liquid swallows and 10 viscous swallows in a seated position after fasting. Then, each subject was asked to ingest $50 \mathrm{~mL}$ distilled water or $10 \mathrm{mg}$ vardenafil dissolved in $50 \mathrm{~mL}$ water, in a double-blind manner. After 25 minutes, the MII-EM study was repeated.

\section{Results}

Eight men received vardenafil and eight subjects received water. Resting and residual lower esophageal sphincter pressures differed significantly only in the vardenafil group (from $18 \pm 6.7$ to $6.6 \pm 5.3 \mathrm{mmHg}, P<0.001$ and from $4.9 \pm 2.6$ to 2.1 $\pm 3.6 \mathrm{mmHg}, P=0.006$, respectively). Mean distal esophageal amplitude decreased significantly only in the vardenafil group (from $86.7 \pm 41.6$ to $34.0 \pm 38.0 \mathrm{mmHg}, P<0.05$ ). Complete bolus transits of liquid and viscous meals decreased significantly only after vardenafil ingestion (from $80.2 \% \pm 13.8 \%$ to $49.4 \% \pm 27.9 \%, P<0.05$ and from $72.8 \% \pm 33.6 \%$ to $21.5 \% \pm 29.0 \%, P=0.01$, respectively).

\section{Conclusions}

Vardenafil decreased esophageal bolus transit in the seated position, despite decreased lower esophageal sphincter pressure.

(J Neurogastroenterol Motil 2012;18:399-405)

Key Words

Manometry; Phosphodiesterase 5 inhibitor; Vardenafil

Received: May 23, 2012 Revised: July 2, 2012 Accepted: July 14, 2012

(c) This is an Open Access article distributed under the terms of the Creative Commons Attribution Non-Commercial License (http://creativecommons. org/licenses/by-nc/3.0) which permits unrestricted non-commercial use, distribution, and reproduction in any medium, provided the original work is properly cited.

*Correspondence: Joon Seong Lee, MD, PhD Institute for Digestive Research, Digestive Disease Center, Soonchunhyang University Hospital, Deasagwan-gil 22, Yongsan-gu, Seoul 140-743, Korea

Financial support: None.

Tel: +82-2-709-9863, Fax: +82-2-795-3687, E-mail: joonlee@schmc.ac.kr

Conflicts of interest: None. 


\section{Introduction}

Sildenafil is an inhibitor of type 5 phosphodiesterase (PDE5). It relaxes or inhibits contraction of smooth muscle by increasing cellular concentrations of cyclic guanosine monophosphate. PDE5 inhibitor has been developed for the treatment of erectile dysfunction. ${ }^{1}$ Previous sildenafil studies mainly demonstrated the inhibition of lower esophageal sphincter (LES) pressure and the amplitudes of peristaltic pressure waves. ${ }^{2-6}$ There were few studies regarding the effect of sildenafil on the bolus transit. ${ }^{7-9} \mathrm{~A}$ newer PDE5 inhibitor, vardenafil (Levitra; Bayer HealthCare AG, Leverkusen, Germany), is similar to sildenafil in terms of structure, pharmacokinetics, time to maximum concentration $(\sim 1$ hour), terminal half-life ( $\sim 4$ hours) and side-effect profile. ${ }^{10}$ Thus, vardenafil and sildenafil might be expected to have similar effects on esophageal function. However, direct effect of vardenafil on the manometric and impedance parameters of healthy volunteers has not been reported yet in the literature review, to our knowledge. Furthermore, most studies did not report the effect of sildenafil on the esophageal motility in seated position but in supine position. Multichannel intraluminal impedance and esophageal manometry (MII-EM) is a new technique that allows simultaneous assessment of esophageal contractile activity and bolus transit. ${ }^{11} \mathrm{We}$ aimed to test the hypothesis that vardenafil would alter esophageal motility function in the seated position using combined MII-EM randomly and in a double-blind manner.

\section{Materials and Methods}

\section{Subjects}

Sixteen healthy volunteers were recruited. The inclusion criteria were an age of 20-60 years and the absence of subjective symptoms, such as dysphagia, globus, regurgitation or chest pain. Exclusion criteria were a history of hypertension, cardiovascular disease, retinitis pigmentosa, liver failure or renal failure, active peptic ulcer, previous major surgery, or an idiosyncratic reaction to vardenafil. Subjects who had used medications that might alter normal esophageal motility within 7 days of the study were also excluded. Fifteen men and one woman were ultimately enrolled. The study protocol was approved by the Institutional Review Board of Soonchunhyang University Hospital, Seoul, Korea. Written informed consent was obtained from each volunteer.

\section{Combined Multichannel Intraluminal Impe- dance and Esophageal Manometry}

All subjects undertook combined MII-EM using a Koenigsberg 9-channel solid-state probe (Sandhill EFT catheter; Sandhill Scientific Inc., Highlands Ranch, CO, USA). The catheter has 5 pressure sensors: two circumferential solid-state pressure sensors located 5 and $10 \mathrm{~cm}$ from the tip and three unidirectional solid-state pressure sensors at 15,20 and $25 \mathrm{~cm}$ from the tip. Segments that measure impedance are $2 \mathrm{~cm}$ in length and centred at 10, 15, 20 and $25 \mathrm{~cm}$ from the tip, straddling the four proximal pressure sensors. All subjects underwent MII-EM in a seated position after an overnight fast. The EFT catheter was inserted trans-nasally and passed into the stomach and then withdrawn slowly until the LES was identified. The catheter was positioned and fixed so that the proximal 4 esophageal pressure sensors and impedance segments were located 5, 10, 15 and 20 $\mathrm{cm}$ above the LES. The volunteers were allowed to become accustomed to the catheter for 30 minutes. They performed 10 liquid swallows of $5 \mathrm{~mL}$ saline at 30-second intervals, followed by 10 viscous swallows at the same intervals. Next, after a basal period of 60 minutes, 8 subjects (vardenafil group) were asked to swallow $10 \mathrm{mg}$ vardenafil dissolved in $50 \mathrm{~mL}$ water, and the other eight subjects (placebo group) were asked to swallow $50 \mathrm{~mL}$ distilled water, randomly and in a double-blind manner. The diminution in LES pressure and the amplitudes of peristaltic pressure waves produced by sildenafil begins within 10 minutes, is maximal at 15-20 minutes and lasts for an hour or less. ${ }^{2}$ Given the similar pharmacokinetics between sildenafil and vardenafil, we repeated the combined MII-EM study in the same manner 25 minutes after the ingestion of vardenafil or placebo.

\section{Data Analysis}

We analysed manometric parameters, such as resting LES pressure, residual LES pressure, peristaltic pressure wave amplitudes, and distal onset velocity. We defined resting LES pressure as the pressure in the high-pressure zone, measured relative to intra-gastric pressure at the end of expiration. The distal onset velocity was calculated from the time it took the peristaltic pressure wave to travel from the most proximal to the most distal pressure-recording site.

We analysed impedance parameters, such as the percentage of complete bolus transit (\% CBT) and total bolus transit time (TBTT), during liquid and viscous swallows. Bolus entry and exit was defined as follows: bolus entry is the point halfway be- 
tween the baseline impedance and the nadir impedance during the presence of the bolus, and bolus exit was considered as the point on the impedance recovery curve where impedance rose to $50 \%$ of the baseline before swallow. Incomplete bolus transit was defined as bolus exit failure at any one of the 3 distal impedancemeasuring sites. TBTT was measured as the interval between bolus entry at the impedance-sensing site $20 \mathrm{~cm}$ above the LES and bolus exit at the impedance-sensing site $5 \mathrm{~cm}$ above the LES. These definitions of impedance parameters were introduced in a report by Tutuian et al. ${ }^{11}$

We compared combined MII-EM parameters between the placebo and the vardenafil groups. We also evaluated the correlation between \% CBT and manometric parameters, such as resting LES pressure, residual LES pressure, distal peristaltic contractile pressure and percentage of peristaltic contraction.

\section{Statistical Methods}

Combined MII-EM parameters of the placebo and the vardenafil groups were compared by the Mann-Whitney U test. Changes in the parameters of each group after the ingestion of vardenafil or placebo were compared using the Wilcoxon signed-ranks test. Correlations between \% CBT and manometric parameters, such as resting LES pressure, residual LES pressure, distal peristaltic contractile pressure and percentage of peristaltic contraction, were also assessed using Pearson's correlation coefficient. All values are expressed as means \pm standard errors of the mean, and statistical significance was set at $P<0.05$.

\section{Results}

\section{Baseline Characteristics}

No significant difference in age or sex was observed between the vardenafil and the placebo groups (Table 1). MII-EM parameters, such as resting and residual LES pressures, distal esophageal wave amplitudes, percentage of peristaltic contractions, and liquid and viscous \% CBTs, did not differ significantly between the vardenafil and the placebo groups before the ingestion of vardenafil or placebo.

\section{Combined Multichannel Intraluminal Impe- dance and Esophageal Manometry: Lower Esophageal Sphincter}

Resting LES pressure decreased significantly, from $18 \pm 6.7$ to $6.6 \pm 5.3 \mathrm{mmHg}$, after the ingestion of vardenafil $(P<$
0.001), but did not change significantly after the ingestion of placebo. Residual LES pressure decreased significantly, from 4.9 \pm 2.6 to $2.1 \pm 3.6 \mathrm{mmHg}$, after the ingestion of vardenafil $(P=$ $0.006)$, but did not change significantly after the ingestion of the placebo. Table 2 shows post-treatment data of the vardenafil and the placebo groups. There was a significant difference in resting LES pressure between the vardenafil and the placebo groups (6.6 \pm 5.3 vs $18.1 \pm 12.6 \mathrm{mmHg}$, respectively, $P=0.038$ ), but no significant difference in residual LES pressure.

\section{Combined Multichannel Intraluminal Impe- dance and Esophageal Manometry: Esopha- geal Body}

Peristaltic wave amplitude decreased significantly after vardenafil ingestion at 5 and $10 \mathrm{~cm}$ above the LES and tended to decrease at $15 \mathrm{~cm}$ above the LES, but showed no significant difference after placebo ingestion (Fig. 1). Mean distal esophageal amplitudes were $86.7 \pm 41.6$ and $34.0 \pm 38.0 \mathrm{mmHg}$ before and after vardenafil ingestion $(P=0.020)$. There was a significant difference in peristaltic wave amplitude between the vardenafil and the placebo groups $(34.0 \pm 38.0$ vs $88.1 \pm 46.2 \mathrm{mmHg}$, respectively, $P=0.010)$.

The percentage of peristaltic contraction decreased significantly, from $92.1 \% \pm 15.5 \%$ to $35.6 \% \pm 40.6 \%$, after the in-

Table 1. Baseline Characteristics of the Vardenafil and the Placebo Groups

\begin{tabular}{lccc}
\hline & $\begin{array}{c}\text { Vardenafil } \\
\text { group }(\mathrm{n}=8)\end{array}$ & $\begin{array}{c}\text { Placebo } \\
\text { group }(\mathrm{n}=8)\end{array}$ & P-value \\
\hline $\begin{array}{l}\text { Age (yr) } \\
\text { Sex (M:F) }\end{array}$ & $31.2 \pm 5.1$ & $31.6 \pm 3.3$ & 0.574 \\
$\begin{array}{l}\text { MII-EM } \\
\text { Mean resting LES pressure } \\
\quad \text { (mean } \pm \text { SE, mmHg) }\end{array}$ & $18.0 \pm 6.7$ & $18.2 \pm 9.3$ & 0.878 \\
$\begin{array}{l}\text { Mean residual LES pressure } \\
\text { (mean } \pm \text { SE, mmHg) }\end{array}$ & $4.9 \pm 2.6$ & $6.4 \pm 8.1$ & 0.799 \\
$\begin{array}{l}\text { Mean distal } \\
\text { esophageal amplitude } \\
\text { (mean } \pm \text { SE, mmHg) }\end{array}$ & $86.7 \pm 41.6$ & $86.2 \pm 29.7$ & 1.000 \\
$\begin{array}{l}\text { Mean percentage of } \\
\text { peristaltic contraction } \\
\text { (mean } \pm \text { SE, \%) }\end{array}$ & $92.1 \pm 15.5$ & $95.1 \pm 7.1$ & 0.878 \\
$\begin{array}{l}\text { CBT for liquids } \\
\text { (mean } \pm \text { SE, \%) }\end{array}$ & $80.2 \pm 13.8$ & $90.7 \pm 15.0$ & 0.161 \\
$\begin{array}{l}\text { CBT for viscous materials } \\
\text { (mean } \pm \text { SE, \%) }\end{array}$ & $72.8 \pm 33.6$ & $66.6 \pm 16.6$ & 0.195 \\
\hline
\end{tabular}

MII-EM, multichannel intraluminal impedance and esophageal manometry; LES, lower esophageal sphincter; CBT, complete bolus transit. 
Table 2. Multichannel Intraluminal Impedance and Esophageal Manometry Parameters After Ingestion of Vardenafil and Placebo

\begin{tabular}{lccc}
\hline & $\begin{array}{c}\text { Vardenafil } \\
\text { group }(\mathrm{n}=8)\end{array}$ & $\begin{array}{c}\text { Placebo } \\
\text { group }(\mathrm{n}=8)\end{array}$ & P-value \\
\hline $\begin{array}{c}\text { Mean resting LES pressure } \\
\text { (mean } \pm \text { SE, mmHg) }\end{array}$ & $6.6 \pm 5.3$ & $18.1 \pm 12.6$ & 0.038 \\
$\begin{array}{c}\text { Mean residual LES pressure } \\
\text { (mean } \pm \text { SE, mmHg) }\end{array}$ & $2.1 \pm 3.6$ & $4.0 \pm 6.5$ & 0.799 \\
$\begin{array}{c}\text { Mean distal } \\
\text { esophageal amplitude } \\
\text { (mean } \pm \text { SE, mmHg) }\end{array}$ & $34.0 \pm 38.0$ & $88.1 \pm 46.2$ & 0.010 \\
$\begin{array}{c}\text { Mean percentage of } \\
\text { peristaltic contraction } \\
\text { (mean } \pm \text { SE, \%) }\end{array}$ & $35.6 \pm 40.6$ & $86.2 \pm 17.8$ & 0.021 \\
$\begin{array}{c}\text { CBT for liquids } \\
\text { (mean } \pm \text { SE, \%) }\end{array}$ & $49.4 \pm 27.9$ & $85.7 \pm 11.0$ & 0.010 \\
$\begin{array}{c}\text { CBT for viscous materials } \\
\text { (mean } \pm \text { SE, \%) }\end{array}$ & $21.5 \pm 29.0$ & $73.3 \pm 18.0$ & 0.003 \\
\hline
\end{tabular}

LES, lower esophageal sphincter; CBT, complete bolus transit.
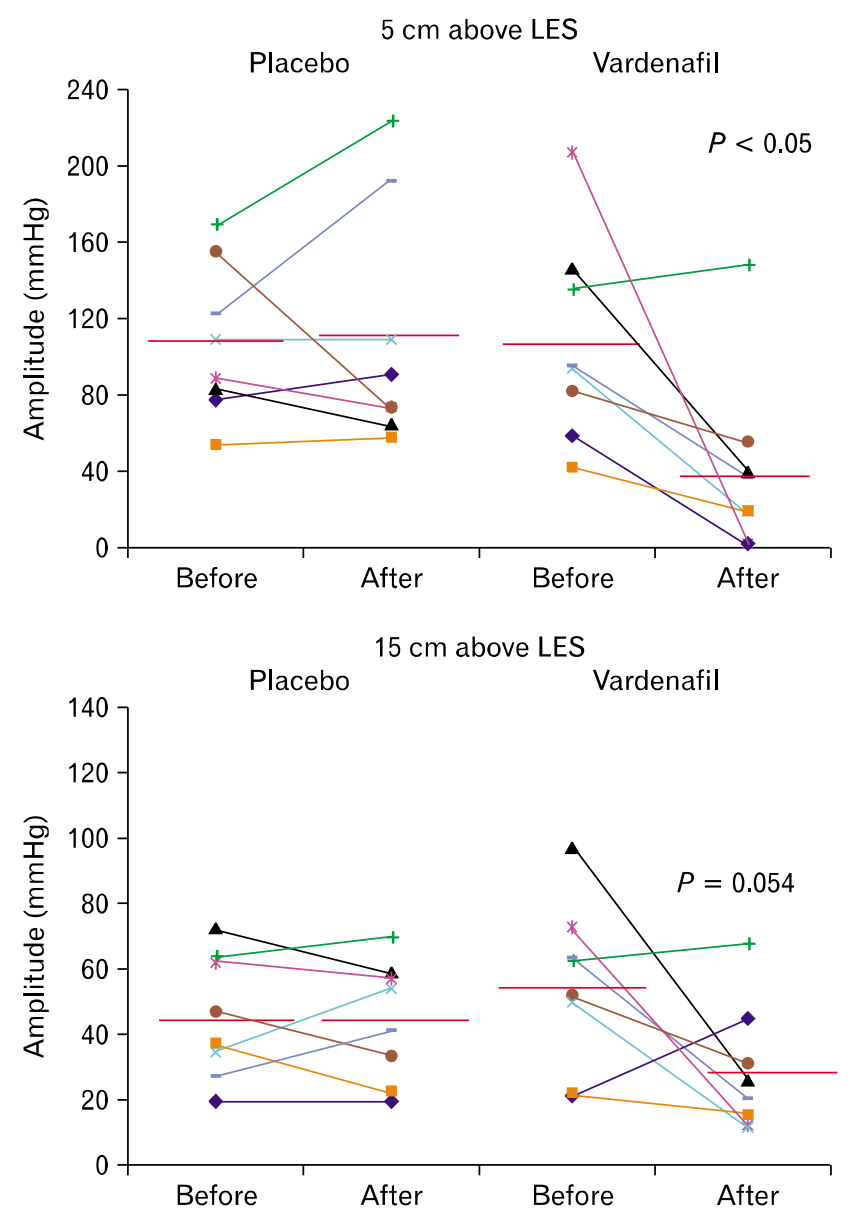

gestion of vardenafil ( $P=0.011)$, but showed no significant change after the ingestion of placebo. There was a significant difference in percentage of peristaltic contraction between the vardenafil and the placebo groups $(35.6 \% \pm 40.6 \%$ vs $86.2 \% \pm$ $17.8 \%$, respectively, $P=0.021$ ). Basal propagation velocities of pressure waves did not differ significantly between the two groups, and did not change significantly after placebo or vardenafil ingestion.

The \% CBT of liquids decreased significantly, from $80.2 \%$ $\pm 13.8 \%$ to $49.4 \% \pm 27.9 \%$, after vardenafil ingestion $(P=$ $0.028)$, but showed no significant change after placebo ingestion (Fig. 2). There was a significant difference in \% CBT of liquids between the vardenafil and the placebo groups $(49.4 \% \pm 27.9 \%$ vs $85.7 \% \pm 11.0 \%$, respectively, $P=0.010$ ). The $\% \mathrm{CBT}$ of viscous materials decreased significantly, from $72.8 \% \pm 33.6 \%$ to $21.5 \% \pm 29.0 \%$, after vardenafil ingestion $(P=0.010)$, but showed no significant change after placebo ingestion. There was

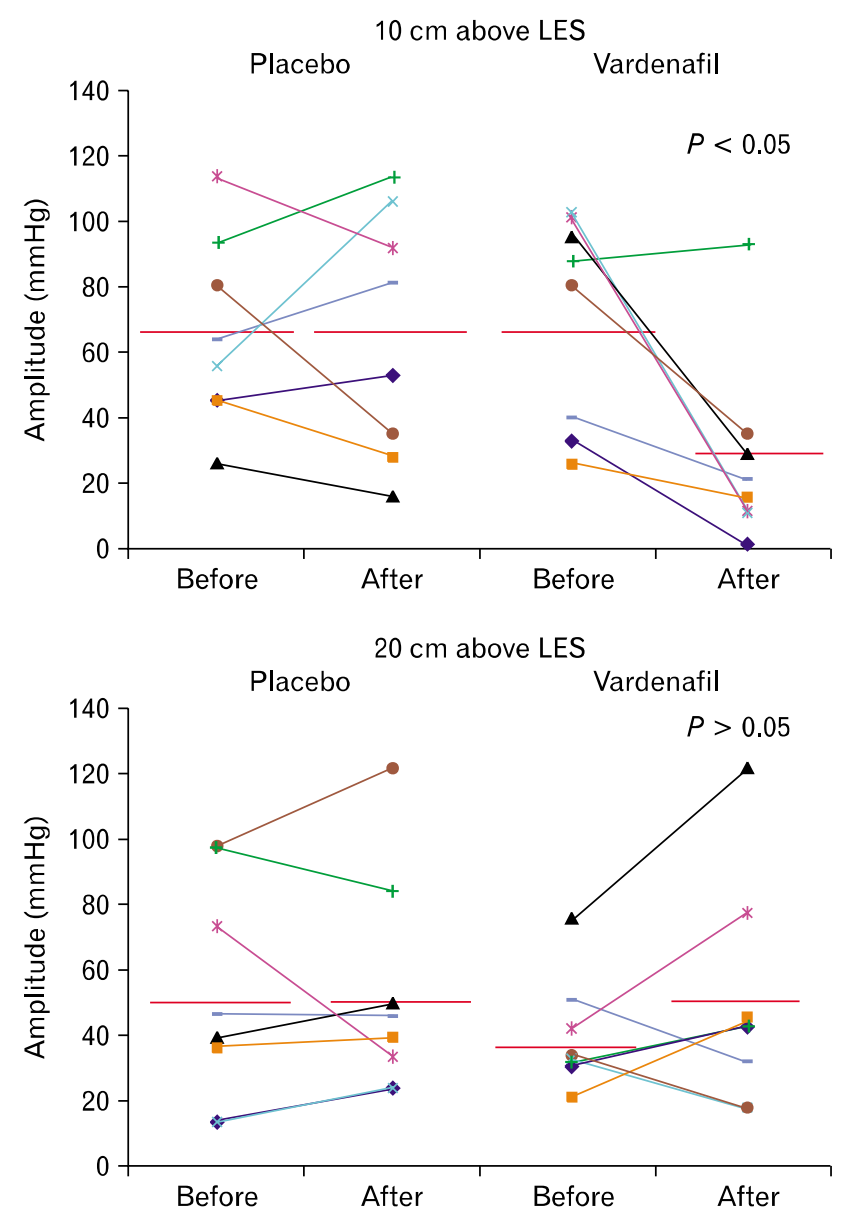

Figure 1. Changes in peristaltic wave amplitude before and after vardenafil or placebo ingestion. Vardenafil significantly decreased the amplitude of peristaltic waves at 5 and $10 \mathrm{~cm}$ above the lower esophageal sphincter (LES) and tended to decrease the amplitude at $15 \mathrm{~cm}$ above the LES. 

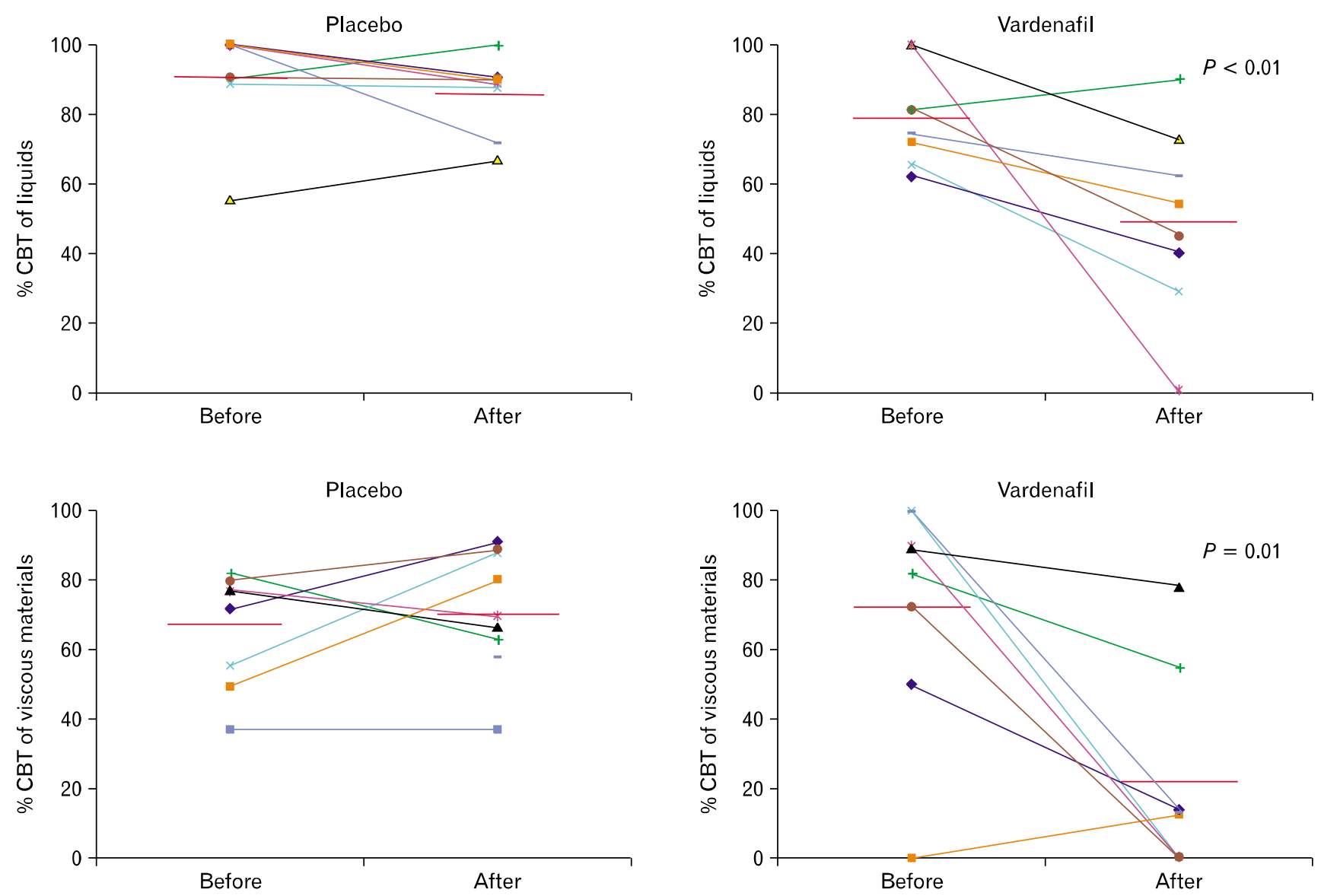

Figure 2. Changes in complete bolus transits (CBTs) of liquid and viscous swallows before and after vardenafil or placebo ingestion. Vardenafil significantly decreased the CBTs of liquid and viscous swallows. \% CBT, percentage of complete bolus transit.

a significant difference in \% CBT of viscous materials between the vardenafil and the placebo groups $(21.5 \% \pm 29.0 \%$ vs $73.3 \%$ $\pm 18.0 \%$, respectively, $P=0.003$ ). The TBTTs of liquid and viscous materials did not differ significantly after the ingestion of vardenafil or placebo.

\section{Correlations between Percentage of Com- plete Bolus Transit and Manometric Parame- ters}

In liquid swallows of all subjects, \% CBT was correlated significantly with distal esophageal contractile pressure $(\mathrm{r}=0.548$, $P=0.001)$ and the percentage of peristaltic contraction $(\mathrm{r}=$ $0.797, P<0.001$ ), but not with resting or residual LES pressure (Fig. 3). In viscous swallows of all subjects, \% CBT was correlated significantly with resting LES pressure $(\mathrm{r}=0.373, P=$ $0.036)$, distal esophageal contractile pressure $(\mathrm{r}=0.548, P=$ $0.001)$, and the percentage of peristaltic contraction $(\mathrm{r}=0.659$, $P<0.001$ ), but not with residual LES pressure (Fig. 3).

\section{Discussion}

In this study, we investigated the effects of the PDE5 inhibitor vardenafil on esophageal motor function and bolus movement of healthy volunteers using combined MII-EM, randomly and in a double-blind manner. PDE5 is an important modulator of smooth muscle contraction. Human and animal studies have shown that it regulates esophageal contraction amplitude by increasing the availability of nitric oxide. ${ }^{12-14}$ Several PDE5 inhibitors, such as sildenafil, vardenafil and tadalafil, are currently available. To date, however, only the effects of sildenafil on esophageal motor function have been evaluated. Most previous studies also focused on manometric parameters regarding the effects of sildenafil. ${ }^{2-7}$

There has been relatively little information in the literature regarding combined MII-EM study of the effect of PDE5 inhibitors on esophageal function. Kim et $\mathrm{al}^{8}$ found that sildenafil 

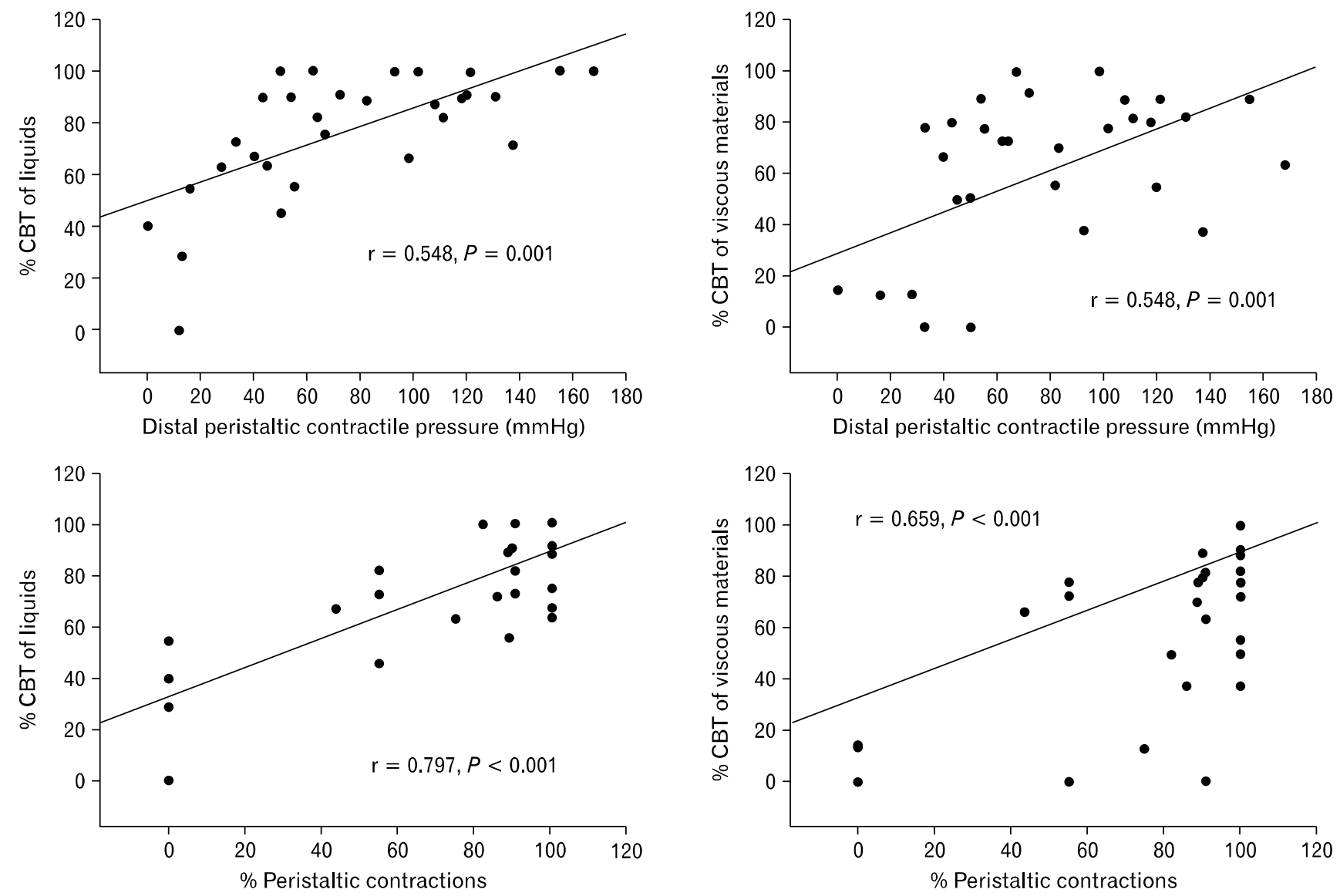

Figure 3. Correlations between percentage of liquid and viscous complete bolus transits (CBTs) and manometric parameters. The percentages of liquid and viscous $\mathrm{CBT}$ s were correlated significantly with distal esophageal contractile pressure and the percentage of peristaltic contraction in all subjects. \% CBT, percentage of complete bolus transit.

decreased the resting LES pressure and prolonged the duration of LES relaxation for the 45 minutes following its ingestion. At 15 minutes, distal onset velocity, TBTT, bolus presence time and segmental transit time were delayed in the mid to distal oesophagus. At 30 minutes, distal onset velocity was restored but bolus presence time and bolus presence time were still delayed in distal smooth muscle segment. At 45 minutes, TBTT and distal onset velocity were restored but bolus presence time and segmental transit time were delayed more in the transition zone. However the study was neither double-blinded nor randomised. The analysis of esophageal motility before and after sildenafil in healthy volunteers was recently performed by Lazarescu et $\mathrm{al}^{9}$ The study indicated sildenafil provoked ineffective peristalsis and incomplete bolus transit in $71 \%$ and $60 \%$ of swallows, respectively. However, the study did not show details of information regarding manometric parameters and bolus transit although the aim of the study was to determine the correlation between the perception of dysphagia and abnormal esophageal function. Furthermore the study was performed in the supine position. To our knowledge, there is little study of vardenafil of esophageal motility in seated position using combined MII-EM to date.

The present study showed that vardenafil decreased resting LES pressure, residual LES pressure, and distal esophageal contraction significantly, consistent with the results of previous sildenafil studies. Our results also showed that vardenafil decreased esophageal bolus transit in a seated position, despite decreased LES pressure. We observed the modest correlation between esophageal contraction and CBT. Because there are a ceiling effect as well as lowest cut off of distal esophageal amplitude predicting esophageal bolus transit, it may be natural that the correlation is modest. Motility patterns can predict the effectiveness of bolus transit and level of stasis to some degree but the relationship between esophageal motility and transit is complex and far from perfect. ${ }^{15}$

The present study has some limitations. Vardenafil has the pharmacokinetics similar to sildenafil. LES pressure, body peristalsis, and bolus transit have exhibited time-dependent changes 
after the ingestion of sildenafil. ${ }^{2,8} \mathrm{We}$ did not evaluate sequential changes in these measurements after vardenafil ingestion. However, combined MII-EM parameters measured 25 minutes after vardenafil ingestion may be sufficient to assess the effects of vardenafil on esophageal function, because these significant changes occurred 10-60 minutes after sildenafil ingestion.

In contrast to conventional manometry, closely spaced pressure channels of high-resolution manometry allow for better assessment of esophageal motor dysfunction. A high-resolution manometry study reported that sildenafil relieved dysphagia and chest pain in a patient with focal spasm missed by conventional manometry. ${ }^{6}$ High-resolution manometry provides an accurate representation of the relationship between closure forces (contractile pressure), clearance force (intrabolus pressure) and outflow resistance (nadir pressure and pressure gradient across the esophagogastric junction). ${ }^{16}$ Further studies using high-resolution manometry should be performed to assess the effect of different types of PDE5 inhibitor on the esophageal motility.

We did not determine whether vardenafil inhibits the esophageal motility and relieve symptoms in spastic esophageal disorders. Our observations do not demonstrate its clinical efficacy for spastic esophageal motor disorder. However, the direct effect of vardenafil on the esophageal motility is similar that of sildenafil reported in previous studies. ${ }^{2,5,9}$ Eherer et $\mathrm{al}^{3}$ reported a case series regarding the efficacy of sildenafil in eleven patients with spastic motility disorders. In the study, sildenafil produced decreases in both LES pressure and the amplitude of esophageal contraction in patients with diffuse esophageal spasm or nutcracker esophagus. Agrawal et $\mathrm{al}^{7}$ reported the efficacy of three PDE5 inhibitors in a patient with nutcracker oesophagus and diffuse esophageal spasm. The patient was started on sildenafil and changed sequentially to vardenafil and tadalafil, with each medication resulting in a marked decrease in chest pain episodes, distal esophageal contraction amplitude, and LES pressure. Fox et $\mathrm{al}^{6}$ reported the cases of two patients with esophageal spasm in whom other conventional treatments had failed, but sildenafil improved symptoms and manometric findings. These findings suggest that vardenafil might be likewise useful for the treatment of spastic motility disorders.

In summary, vardenafil decreased resting and residual LES pressures, distal esophageal contraction, and bolus transit. Prospective placebo-controlled clinical trials are also required to determine whether vardenafil is effective in the treatment of spastic esophageal motility disorders.

\section{References}

1. Moreland RB, Goldstein I, Traish A. Sildenafil, a novel inhibitor of phosphodiesterase type 5 in human corpus cavernosum smooth muscle cells. Life Sci 1998;62:PL 309-318.

2. Bortolotti M, Mari C, Giovannini M, Pinna S, Miglioli M, Pandolfo N. Effects of sildenafil on esophageal motility of normal subjects. Dig Dis Sci 2001;46:2301-2306.

3. Eherer AJ, Schwetz I, Hammer HF, et al. Effect of sildenafil on oesophageal motor function in healthy subjects and patients with oesophageal motor disorders. Gut 2002;50:758-764.

4. Lee JI, Park H, Kim JH, Lee SI, Conklin JL. The effect of sildenafil on oesophageal motor function in healthy subjects and patients with nutcracker oesophagus. Neurogastroenterol Motil 2003;15:617-623.

5. Rhee PL, Hyun JG, Lee JH, et al. The effect of sildenafil on lower esophageal sphincter and body motility in normal male adults. Am J Gastroenterol 2001;96:3251-3257.

6. Fox M, Sweis R, Wong T, Anggiansah A. Sildenafil relieves symptoms and normalizes motility in patients with oesophageal spasm: a report of two cases. Neurogastroenterol Motil 2007;19:798-803.

7. Agrawal A, Tutuian R, Hila A, Castell DO. Successful use of phosphodiesterase type 5 inhibitors to control symptomatic esophageal hypercontractility: a case report. Dig Dis Sci 2005;50:2059-2062.

8. Kim HS, Conklin JL, Park H. The effect of sildenafil on segmental oesophageal motility and gastro-oesophageal reflux. Aliment Pharmacol Ther 2006;24:1029-1036.

9. Lazarescu A, Karamanolis G, Aprile L, De Oliveira RB, Dantas R, Sifrim D. Perception of dysphagia: lack of correlation with objective measurements of esophageal function. Neurogastroenterol Motil 2010;22:1292-1297. e336-e337.

10. Wright PJ. Comparison of phosphodiesterase type 5 (PDE5) inhibitors. Int J Clin Pract 2006;60:967-975.

11. Tutuian R, Vela MF, Shay SS, Castell DO. Multichannel intraluminal impedance in esophageal function testing and gastroesophageal reflux monitoring. J Clin Gastroenterol 2003;37:206-215.

12. Anand N, Paterson WG. Role of nitric oxide in esophageal peristalsis. Am J Physiol 1994;266(1 Pt 1):G123-G131.

13. Konturek JW, Thor P, Lukaszyk A, Gabryelewicz A, Konturek SJ, Domschke W. Endogenous nitric oxide in the control of esophageal motility in humans. J Physiol Pharmacol 1997;48:201-209.

14. Murray JA, Ledlow A, Launspach J, Evans D, Loveday M, Conklin $\mathrm{JL}$. The effects of recombinant human hemoglobin on esophageal motor functions in humans. Gastroenterology 1995;109:1241-1248.

15. Bogte A, Bredenoord AJ, Oors J, Siersema PD, Smout AJ. Relationship between esophageal contraction patterns and clearance of swallowed liquid and solid boluses in healthy controls and patients with dysphagia. Neurogastroenterol Motil 2012;24:e364-e372.

16. Fox MR, Bredenoord AJ. Oesophageal high-resolution manometry: moving from research into clinical practice. Gut 2008;57:405-423. 